\title{
DENTAL ANXIETY AMONG DENTAL STUDENTS
}

\author{
Donka G. Kirova \\ Department of Oral Surgery, Faculty of Dental Medicine, \\ Medical University - Plovdiv, Bulgaria
}

\begin{abstract}
Dental anxiety and dental fear are major factors causing much troubles for the people attending to their own personal health. Statistics show that the 25-26-year-olds experience higher dental anxiety than others. This can be accounted for by the diverse, intense effects of a number of psychological factors in this age range that can cause dental fear and dental anxiety.

The aim of the present study was to survey the dental anxiety levels among the students of the Faculty of Dentistry in Plovdiv and determine whether they change throughout the course of study.
\end{abstract}

Material and methods. The self-reported assessment scale developed by N. Corah, the Dental Anxiety Scale (DAS) was used in the study; it was applied in the form of a questionnaire containing data on gender, age, education. A total of 535 students of all years in the Faculty of Dentistry in Plovdiv were recruited in the study; they were interviewed either individually or in groups.

Results and discussion. Anxiety-free students were the most numerous group in the sample $(369,63.08 \%)$, which were followed by students showing moderate anxiety. The mean DAS score of the whole sample was $7.83 \pm 0.12$; the mean scores by groups were as follows: $8.37 \pm 0.26$ for the first year students $\left(\mathrm{n}_{1}\right), 7.34 \pm 0.19$ for the second, third and fourth year students $\left(\mathrm{n}_{2}\right), 7.82 \pm 0.16$ for the fifth and sixth year students $\left(n_{3}\right)$. Twenty five (4.27\%) students experienced high anxiety and 11 students (1.88\%) - severe anxiety. Analysis of the mean dental anxiety scores for the three groups showed that fear of dental treatment statistically significantly declined with each successive year of study $(\mathrm{P}=0.008)$.

Conclusions: Dental students have a significantly higher level of dental anxiety at the beginning of their training than at its end $(\mathrm{P}<0.01)$. Enhancing education and awareness affects favourably dental anxiety.

Keywords: dental anxiety, dental fear of students, dental anxiety scales

\section{INTRODUCTION}

Dental anxiety and fear are considered the major reasons for avoidance of dental care thus resulting in deterioration of their personal oral health. These conditions occur in people of any age and social status. Statistics show that it is the 25-26-year-olds that tend to experience higher dental anxiety than other people (9-11). This can be accounted for by the diverse effects of a number of psychological factors in this age range that can induce dental fear and dental anxiety. Students constitute a large part of this age group which includes also dental students. Several studies on such contingents have demonstrated that moderate dental anxiety varies from group to group - $11.9 \%, 11.22 \%, 13.27 \%$, $13.58 \%$, and high dental anxiety (DAS $\geq 13$ ) - 19\%, 27.2\%, $32 \%(2,8,14)$. Women tend to be affected by dental anxiety more often than men are, although the data fail to reach statistical significance in most cases $(12,14,15)$. Major procedures that are considered to induce anxiety are the local anaesthetic injection and teeth drilling $(1,2,12)$. Al-Omari studied students of different majors and found that dental students have lower levels of dental anxiety in comparison with students in other majors.

The present study aims to investigate the dental anxiety in the students of the Faculty of Dentistry in Plovdiv and determine whether it changes over the entire course of study.

\section{MATERIAL AND METHODS.}

The study used the self-reported assessment test of Corah's Dental Anxiety Scale (DAS) $(4,5)$. The questionnaire consists of four questions each with five possible responses, measured in points of 1 to 5 . The overall maximum score is 20. The final assessment of anxiety is given by the sum of points awarded for each question: less than 8 points is considered to indicate no anxiety; 9 to 12 points - moderate anxiety, 13 to 14 points - high anxiety, 15 to 20 points - severe anxiety bordering on phobia. N Corah considers patients to suffer from high dental anxiety if they score 13 to 20 points. The reason we chose this scale as an instrument of assessment was because it is rather brief, accessible and easily understood.

585 students from the Faculty of Dentistry in Plovdiv completed the questionnaire. The population included students of all years of study and these were divided into three groups: $\mathrm{n}_{1}=166$ first-year students, $\mathrm{n}_{2}=183$ second-, thirdand fourth-year students and $n_{3}=236$ fifth- and sixth-year students.

Data were analysed using SPSS v17 and parametric and non-parametric methods. Significance level was set at $\mathrm{P}<0.05$. 


\section{RESULTS}

The study sample had 229 men and 356 women (mean age $22.29 \pm 0.11$ ) (Fig. 1).

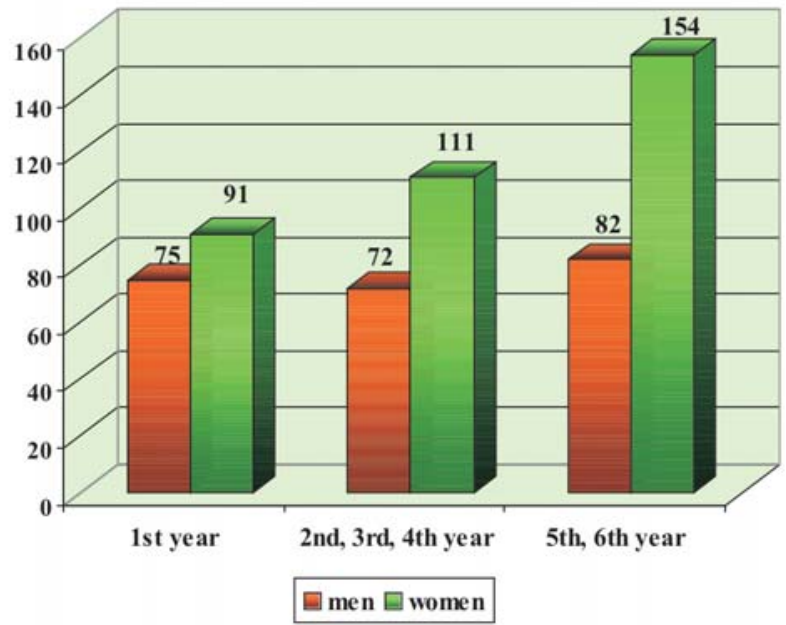

Fig. 1. Distribution of studied students by year of study and gender.

The distribution of respondents by type of dental anxiety as assessed with DAS is shown in Fig. 2. The anxietyfree respondents were the most numerous $(369,63.8 \%) ; 180$ $(30.77 \%)$ students showed moderate dental anxiety. High dental anxiety was experienced by $25(4.27 \%)$ students, while $11(1.88 \%)$ had severe anxiety.

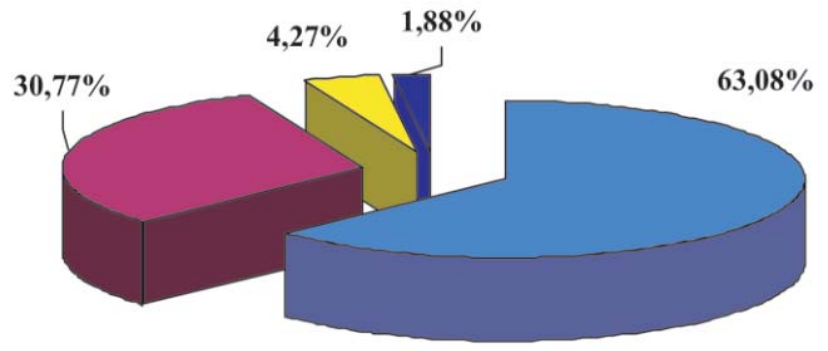

$\square$ no anxiety $\square$ moderate $\square$ high $\square$ severe

Fig. 2. Distribution of respondents by dental anxiety level.
Figure 3 shows the distribution of students by dental anxiety level and gender.

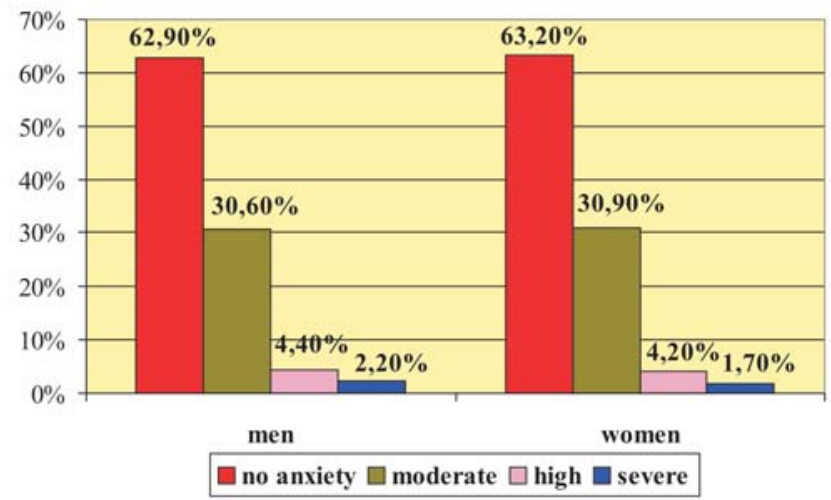

Fig. 3. Distribution of respondents by gender and degree of anxiety.

We found no significant difference in dental anxiety in gender $\left(\chi^{2}=0.20, \mathrm{df}=3, \mathrm{P}>0.05\right)$. The mean DAS score of the whole sample was $7.83 \pm 0.12$; the mean scores by groups were as follows: $8.37 \pm 0.26$ for the first-year students $\left(\mathrm{n}_{1}\right)$, $7.34 \pm 0.19$ for the second-, third- and fourth-year students $\left(\mathrm{n}_{2}\right), 7.82 \pm 0.16$ for the fifth- and sixth-year students $\left(\mathrm{n}_{3}\right)$. By gender these points were $7.87 \pm 2.86$ for men, and $7.80 \pm 2.82$ for women. Analysis of the mean dental anxiety scores for the three groups showed that fear of dental treatment statistically significantly declined with each successive year of study (Table 1).

Table 1. Mean dental anxiety score of students by year of study.

\begin{tabular}{|l|c|c|c|}
\hline Year of study & Number of respondents & $\begin{array}{c}\text { Mean score } \\
\overline{\mathrm{x}} \pm \mathrm{S}_{\overline{\mathrm{x}}}\end{array}$ & Kruskal-Wallis Test \\
\hline 1st year & 166 & $8.37 \pm 0.26$ & \multirow{2}{*}{$\mathrm{P}=0.008$} \\
\hline 2nd, 3rd and 4th year of study & 183 & $7.34 \pm 0.19$ & \\
\hline 5th and 6th year of study & 236 & $7.82 \pm 0.16$ & \\
\hline Total & 585 & $7.83 \pm 0.12$ & \\
\hline
\end{tabular}




\section{DISCUSSION}

Most of the students in the studied contingent were anxiety-free $(369,63.08 \%)$. High anxiety (DAS $=13-20)$ was experienced by $36(6.15 \%)$. This was not consistent with the results of other studies which found a considerably greater percentage of students with dental anxiety $(2,6,10,11,13)$ and that women are more prone to experience dental fear than men are. In our study we found no difference between the two genders.

If we consider the dental anxiety expressed in mean score points, first year students score much greater results than the students in the other years of study which is a direct indication that young dentists have greater fear from a dental treatment than senior students have. These findings are fully consistent with the results of other researchers that dental anxiety declines with each successive year of study $(1,15)$.
This can be explained by the increased awareness and education of the students, their professional development and acquired clinical experience. The effect of some factors on dental anxiety is quite likely to decrease or even be completely lost. Such factors could include the managed pain in a conservative treatment and in a surgical treatment, the enhanced knowledge of the methods and approaches to the treatment. This can be the direction of our efforts to prevent and decrease dental anxiety among patients.

\section{CONCLUSIONS}

1. Dental students have a significantly higher level of dental anxiety at the beginning of their training than at its end $(\mathrm{P}<0.01)$.

2. Enhancing education and awareness affects favourably dental anxiety.

\section{REFERENCES:}

1. Acharya S, Sangam DK. Dental anxiety and its relation ship with selfperceived health locus of control among Indian dental students. Oral Health Prev Dent. 2010; 8(1): 9-14. [PubMed]

2. Al-Omari WM, Al-Omiri MK. Dental anxiety among university students and its correlation with their field of study. $J$ Appl Oral Sci. 2009; 17(3): 199-03. DOI: $10.1590 / \mathrm{S} 1678-77572009000300013$ CrossRef] [PubMed]

3. Barberia E, Fernandez-Frias C, Suarez-Clua C, Saavedra D. Analysis of anxiety variables in dental students. Int Dent J 2004; 54(6): 445-9. [PubMed]

4. Corah NL. Dental anxiety. Assessment, reduction and increasing patient satisfaction. Dent Clin North Am 1988 Oct;32(4):779-90. [PubMed]

5. Corah NL, Pantera RE. Controlled study of psychological stress in a dental procedure. J Dent Res 1968 JanFeb;47(1):154-7. DOI: 10.1177/ 00220345680470011001 CrossRef] [PubMed]

6. Halonen H, Salo T, Hakko H, Rasanen P. Association of dental anxiety to personality traits in a general population sample of Finish university students. Acta Odontol Scand 2011 Jul 8; [doi:10.3109/ $00016357.2011 .598182 \quad$ CrossRef] [PubMed].

7. Yusa H, Onizawa K, Hori M, Takeda S, Takeda H, Fukushima S, Yoshida H. Anxiety measurements in university students undergoing third molar extraction. Oral Surg Oral Med Oral Pathol Oral Radiol Endod 2004 Jul;98(1):23-7.

[doi:10.1016/j.tripleo.2003.12.017 CrossRef] [PubMed]

8. Kaakko T, Milgrom P, Coldwell S, Getz T, Weistein Ph, Ramsay D. Dental fear among university students: Implications for pharmacological research. Anesth Prog. 1998 Spring;45:62-67. [PubMed]

9. Kirova D, Atanasov D, Lalabonova $\mathrm{Hr}$, Janevska S. Dental anxiety in adults in Bulgaria. Folia Medica(Plovdiv), 2010 Apr-Jun;52(2):49-56. [PubMed]

10. Locker D, Thomson WM, Poulton R. Onset of and patterns of change in dental anxiety in adolescence and early adulthood: a birth cohort study. Community Dent Health 2001 Jun;18(2):99-104.

\section{[PubMed]}

11. Locker D, Liddell A, Burman D. Dental fear and anxiety in an older adult population. Community Dent Oral Epidemiol. 1991 Apr;19(2):120-4. [PubMed]

12. Rao A, Sequeire PS, Peter S. Characteristics of dental fear amongst dental and medical students. Indian J Dent Res. 1997 Oct-Dec;8(4):111-4. [PubMed]

13. Skaret E, Kvale G, Raadal M. General self-efficacy, dental anxiety and multiple fears among 20-year-olds in Norway. Scand J Psychol 2003 Sep;44(4):331-7. [DOI: 10.1111/14679450.00352 CrossRef] [PubMed]

14. Shaikh MA, Kamal A. Over dental anxiety problems among university students: perspective from Pakistan. $J$ Coll Physicians Surg Pak. 2011 Apr;21(4):2378. [PubMed]

15. Peretz B, Mann J. Dental anxiety among Israel dental students: a 4-year longitudinal study. Eur J Dent Educ. 2000 Aug;4(3):133-7. [DOI: 10.1034/j.16000579.2000.040308.x CrossRef] [PubMed]

\footnotetext{
Adrress for correspondence:

Donka Kirova

Department of Oral Surgery, Faculty of Dental Medicine,

Medical University - Plovdiv

3, Hristo Botev Blvd., 4002 Plovdiv, Bulgaria

e-mail: doda_bg@yahoo.com,doda_bg@abv.bg,
} 